\title{
A CONSOLIDAÇÃO DO CENTRO DE MEMÓRIA DOM BOSCO EM PETROLINA COMO ESPAÇO HISTÓRICO-EDUCATIVO
}

\author{
Jardel Costa Pereira \\ Universidade do Estado de Minas Gerais \\ jardelcostper@gmail.com \\ Rozângela do Nascimento Pereira \\ Universidade do Estado da Bahia \\ rozangelaedu@outlook.com \\ Rosa Santos Mendes da Silva \\ Universidade do Estado da Bahia \\ rosa.sns@hotmail.com
}

\begin{abstract}
RESUMO
Há várias formas de escrever a História da Educação. A maneira escolhida e apresentada nesse trabalho é o Memorial Dom Bosco localizado na cidade de Petrolina PE, que foi considerado como um espaço de intervenção para a preservação da memória escolar. Um foco importante desse trabalho é perceber, por meio da História Oral, a visão de sujeitos históricos na consolidação desse memorial. Concluiu-se que, a organização de fontes documentais e de arquivo, contribuem para a consolidação de centros de memória educativos e pedagógicos, sendo possibilidades e locais de aprendizado/treinamento de futuros historiadores/pesquisadores; uma prática que pode, unida à teoria e com um rigor metodológico, atrair jovens estudantes das áreas de Pedagogia e da História.
\end{abstract}

Palavras-chave: Memorial Dom Bosco. História Oral. Preservação.

\section{THE CONSOLIDATION OF THE DOM BOSCO MEMORY CENTER IN PETROLINA AS HISTORICAL-EDUCATIONAL SPACE}

\begin{abstract}
There are several ways to write the History of Education. The way chosen and presented in this work is the Memorial Dom Bosco located in the city of Petrolina PE, which was considered as an intervention space for the preservation of school memory. An important focus of this work is to perceive, through Oral History, the vision of historical subjects in the consolidation of this memorial. It was concluded that the organization of documentary and archival sources contribute to the consolidation of educational and pedagogical memory centers, being possibilities and places of learning / training for future historians / researchers; a practice that can, together with theory and with methodological rigor, attract young students from the areas of Pedagogy and History.
\end{abstract}

Keywords: Dom Bosco Memorial. Oral History. Preservation. 


\section{LA CONSOLIDACIÓN DEL CENTRO DE MEMORIA DE DOM BOSCO EN LA PETROLINA COMO ESPACIO HISTÓRICO-EDUCACIONAL}

\section{RESUMEN}

Hay varias formas de escribir la Historia de la Educación. La forma escogida y presentada en ese trabajo es el Memorial Dom Bosco ubicado en la ciudad de Petrolina PE, que fue considerado como un espacio de intervención para la preservación de la memoria escolar. Un foco importante de ese trabajo es percibir, por medio de la Historia Oral, la visión de sujetos históricos en la consolidación de ese memorial. Se concluyó que, la organización de fuentes documentales y de archivo, contribuyen a la consolidación de centros de memoria educativos y pedagógicos, siendo posibilidades y lugares de aprendizaje / entrenamiento de futuros historiadores / investigadores; una práctica que puede, unida a la teoría y con un rigor metodológico, atraer jóvenes estudiantes de las áreas de Pedagogía y de la Historia.

Palabras clave: Memorial Dom Bosco. Historia Oral. Preservación.

\section{LA CONSOLIDATION DU CENTRE DE MÉMOIRE DOM BOSCO DE PETROLINA EN TANT QU'ESPACE HISTORIQUE-ÉDUCATIF}

\section{RÉSUMÉ}

Il y a plusieurs façons d'écrire l'histoire de l'éducation. La manière choisie et présentée dans cet ouvrage est le Mémorial Dom Bosco situé dans la ville de Petrolina, PE, qui a été considéré comme un espace d'intervention pour la préservation de la mémoire de l'école. Un objectif important de ce travail est de percevoir, à travers l'histoire orale, la vision des sujets historiques dans la consolidation de ce mémorial. Il a été conclu que l'organisation de sources documentaires et archivistiques contribuait à la consolidation des centres de mémoire éducatifs et pédagogiques, en tant que possibilités et lieux d'apprentissage / de formation pour les futurs historiens / chercheurs; une pratique qui peut, avec la théorie et la rigueur méthodologique, attirer de jeunes étudiants des domaines de la pédagogie et de l'histoire.

Mots-clés: Mémorial Dom Bosco. Histoire orale. La conservation.

\section{INTRODUÇÃO}

O objetivo desse trabalho é apresentar as implicações conceituais e metodológicas acerca de um patrimônio educativo - Memorial Dom Bosco - localizado no interior de um colégio privado vinculado à Diocese de Petrolina, no Estado de Pernambuco, Brasil, pois um memorial escolar pode contribuir na reconstrução histórica de uma instituição e na preservação da memória escolar, resultando na construção da história da educação local. 
Num recente trabalho de conclusão de curso de graduação no Curso de História da Universidade de Pernambuco, campus Petrolina, Santos (2015, p. 43-44), membro do Grupo de Estudos e de Pesquisas sobre Educação Escolar e não Escolar no Sertão Pernambucano (GEPESPE), participante desse projeto e pesquisador no Memorial Dom Bosco, destacou a importância do memorial para a escrita da história da Educação, sendo que ao citar Furtado (2009), certifica que as instituições escolares são um espaço muito importante para as pesquisas em história “da educação, porque é neste espaço que se encontra os arquivos produzidos pela própria instituição, dando possibilidade de se analisar esse material e construir uma memória deste local"

No parecer de Mogarro, referencial teórico importante para esse trabalho:

Os arquivos escolares motivam profundas preocupações relativamente à salvaguarda e preservação dos seus documentos, que constituem instrumentos fundamentais para a história da escola e a construção da memória educativa. A sua importância tem vindo a ser reconhecida, conduzindo a uma reflexão sobre a sua preservação, as condições de instalação, a organização correta dos documentos e o acesso às informações que nele estão contidas. Os arquivos escolares constituem o repositório das fontes de informação diretamente relacionadas com o funcionamento das instituições educativas, o que lhes confere uma importância acrescida nos novos caminhos da investigação em educação, que colocam estas instituições numa posição de grande centralidade para a compreensão dos fenômenos educativos e dos processos de socialização das gerações mais jovens. (MOGARRO, 2006, p. 71).

Investigar a importância do acervo do Memorial Dom Bosco e a sua contribuição para o contexto social, cultural e educacional da Cidade de Petrolina e da região, torna-se relevante, pois nada ainda foi feito nesse sentido, o que é um problema e um desafio para vários historiadores da educação, como descrito por Mogarro:

Os historiadores da educação só recentemente se têm vindo a ocupar da arqueologia material da escola, dando atenção aos silêncios da história do ensino e superando o esquecimento da intra-história da escola e da especificidade própria das instituições educativas. (MOGARRO, 2006, p. 79).

São poucas as escolas no Brasil e até mesmo em vários países que contam com um local específico para guardar e preservar a sua arqueologia escolar, o que não é o caso do Colégio Dom Bosco em Petrolina, pois além de possuir um memorial, a sua idealizadora ainda estava atuante como sua diretora quando no início do projeto. Um outro desafio é interpretar e lidar esse presente tão real, onde podem desvelar as especulações, as interpretações e as deduções, ficando somente o que realmente é, nos seus propósitos e suas intenções. 
Nessa direção encontra-se também o pensamento de Mogarro, que ao escrever sobre uma realidade dos arquivos escolares de Portugal, acena para um campo geral da história da educação que vem se renovando, seja por meio de novas abordagens, novos locais, novos métodos de pesquisa e claro, velhos e novos desafios ${ }^{1}$ :

Situamo-nos numa zona de fronteira, de cruzamento, das novas perspectivas da história da educação, da história cultural, da história social e também das ciências da educação. Assiste-se a uma renovação das problemáticas teóricas e de uma reinvenção dos terrenos de pesquisa, das fontes de informação, das práticas de investigação e do apetrechamento metodológico, em que a perspectiva historiográfica se afirma face às antigas abordagens de matriz essencialmente sociológica. A afirmação de uma história que se reclama de um pensamento cultural crítico estabelece uma agenda de diálogo entre as preocupações do presente e as realidades do passado, num esforço de compreensão em que se interrogam estas últimas para alcançar a inteligibilidade dos tempos presentes. (MOGARRO, 2006, p. 79).

Entender um arquivo escolar, a lógica de sua construção e de sua organização, da exposição de sua materialidade, da concentração em alguns atores sociais ou até mesmo da negligência de outros, das suas intenções explícitas ou implícitas, é poder, no aqui e agora, dar sentido real e não ilusório, do que vem sendo feito e realizado na preservação da história da escola, por isso o projeto desenvolvido na Universidade de Pernambuco tem valorizado muito a memória viva, atual e presente, por meio de depoimentos orais, pois muito se tem perdido de nossa história por causa da dependência de documentos escritos, esquecendo-se de que, quando o documento não existe, os relatos podem preencher essas lacunas. Nesse contexto, para Le Goff (1994, p. 477), “[...] é da análise e interpretação dos registros, da memória que se reconstitui a história, pois é na memória, onde cresce a história, que por sua vez a alimenta, procura salvar o passado para servir o presente e o futuro".

Nessa pesquisa optou-se pela história oral, que consiste na utilização de entrevista como fonte de pesquisa. De acordo com Lozano (2004 apud ROCHA, 2014), a história oral é vista como método particular, mas não exclusivamente, pois é considerada um meio de estabelecer relações de maior qualidade e profundidade com as pessoas entrevistadas.

Nas lembranças, guardadas em algum lugar da memória, emergem marcas de um tempo e de uma época, são modos de pensar, de sentir e de viver os desafios enfrentados no cotidiano da

\footnotetext{
${ }^{1} \mathrm{O}$ mesmo trabalho realizado no Colégio Dom Bosco foi proposto a ser desenvolvido numa outra instituição privada confessional de Petrolina, mas não se obteve o mesmo êxito, pois não deram resposta da possibilidade ou impossibilidade de concretizá-lo. Essas atitudes impedem que outros dados sobre a história da educação sejam escritos, ficando assim incompletas outras partes do sistema educacional a ser pesquisado.
} 
vida, conforme indicado por Ávila, Silva e Rocha no artigo intitulado 'Memórias de professoras de escolas rurais em Juazeiro - BA e Petrolina - PE (1950-1970). Neste sentido, afirmam as autoras, as lembranças do passado carregam na memória uma sensibilidade especial, pois: “[...] obriga cada um a relembrar e a reencontrar o pertencimento, princípio e segredo da identidade [...] a memória e a vida sempre carregada por grupos vivos e, nesse sentido, ela está em permanente evolução, aberta à dialética da lembrança e do esquecimento" (NORA, 1993, p.19).

Por isso torna-se imprescindível conhecer a história do lugar e dos personagens, com suas representações e papéis políticos, sociais, culturais e educacionais.

\section{DESENVOLVIMENTO}

Este trabalho está vinculado ao Grupo de Estudos e Pesquisas sobre Educação Escolar e não Escolar no Sertão Pernambucano (GEPESPE), vinculado ao NEPHEL - Núcleo de Estudo e Pesquisa em História Educação e Linguística da Universidade de Pernambuco (UPE). Por meio de um projeto de preservação e de recuperação de documentos trabalhou-se no Memorial Dom Bosco de maneira interventiva e de forma interdisciplinar entre os Cursos de Pedagogia e de História da Universidade de Pernambuco, localizado na cidade de Petrolina, no Estado de Pernambuco.

O Memorial Dom Bosco foi fundado no dia 14 de agosto de 1996 por Terezinha Teixeira Coelho, diretora do Colégio Dom Bosco, com o intuito de conservar a memória da instituição, objetivando preservar a história da educação local.

Terezinha Teixeira Coelho foi coerente com o seu ponto de vista sobre o memorial e a sua documentação, tendo permitido a intervenção dos historiadores no acervo, como também fornecendo todo o material necessário para conservação de determinadas fontes. Antes de deixar a direção do Colégio Dom Bosco, após 40 anos de exercício dessa função, ela ainda concedeu uma entrevista como também foi entrevistada no programa 'Educação Prioridade Nacional' que pertence ao Colégio Dom Bosco, na Rádio Emissora Rural da Diocese de Petrolina, que está no ar desde de 1992, em que se referiu ao projeto, apresentando-o com as seguintes palavras:

[...] fez pesquisa no Dom Bosco que é, acredito, o centro de registro importante da história de seu povo, história da educação da Diocese de Petrolina, e não somente da Diocese pois o Colégio Dom Bosco faz parte da história da cidade, está interligado. Nosso obrigada. Lá no memorial, as pessoas devem procurar conhecer mais, visitar e ver o acervo importantíssimo que tem para reconhecer o valor que a nossa Diocese tem sobre o papel da educação, quantos passaram... quantos que foram... Na pessoa de Dom Malan, que foi 
o grande idealizador desse centro cultural que está localizado na Rua Coronel Amorim, que só fez história, só fez bem para cidadãos e cidadãs e que hoje a gente aplaude. [...]. Obrigado pelo grande trabalho que vocês fizeram lá no Colégio Dom Bosco, lá no memorial. (Entrevista realizada ao vivo na Rádio Rural (Cf. o site: http://am730.com.br/) no dia 19 de Dezembro de 2015).

Segundo observa Teresinha Teixeira Coelho ${ }^{2}$, em entrevista realizada aos 17 de dezembro de 2015 por Rozângela do Nascimento Pereira, o motivo que a levou a fundação do Memorial Dom Bosco foi o seguinte:

Quando assumi a direção do Colégio Dom Bosco, eu pensei muito em como registrar essa história. Assumi em 1976 e então as conquistas estavam acontecendo sempre no Colégio D. Bosco, com trabalho dos alunos, com troféus, com informações, por ocasião dos 70 anos do colégio Dom Bosco, eu disse: vai ser este ano, porque eu aprecio muito a cultura, e pra mim o memorial é um elo de cultura para o povo, e o povo sem memória é um povo sem história, e não comportava mais na minha sala colocar os troféus, os registros importantes da história do Colégio D. Bosco, então eu pensei, e hoje está o Memorial D. Bosco com um acervo muito positivo, muito bom, que tem como objetivo os alunos conhecerem a verdadeira história do D. Bosco e a comunidade também, porque o D. Bosco pertence à comunidade é um colégio que não tem dono, ele é da comunidade de Petrolina. (COELHO, 2015).

No parecer da diretora fica explícito a função que ela apresenta para um memorial e especificamente para o escolar, o qual ela fundou: público, ou seja, aberto a todos da comunidade e fomentador de cultura, trazendo informações e conhecimento, inserindo assim a escola na vida do povo da cidade e trazendo para o memorial a população petrolinense, pois muitos se veem ali representados em seus pais, filhos, netos e conhecidos que fizeram história escolar no Colégio Dom Bosco.

A própria arquitetura do memorial apresenta essa lógica de abertura à comunidade, sendo o prédio separado do local onde funciona a escola e bem de frente do portão principal, sendo que se localiza mais facilmente a sua entrada do que a porta principal do recinto escolar.

Teresinha Teixeira Coelho nasceu aos 22 de Novembro de 1944, sendo que tinha 52 anos quando inaugurou o Memorial Dom Bosco, tem uma postura moderna e uma formação na área de

\footnotetext{
${ }^{2}$ Diretora do Colégio Dom Bosco, teve e tem uma atuação importante na cidade de Petrolina PE: “Coordenadora da Fraternidade Cristã dos Deficientes, Secretária da Sociedade Pró-Menor, Secretária da Equipe de Coordenação da Diocese de Petrolina; Secretária do Conselho Diocesano de Pastoral; Vice-Presidente do Conselho Municipal de Defesa das Crianças e Adolescentes; Conselheira da AEC-Pernambuco; Representante Regional do Sindicato de Estabelecimentos de Ensino do Estado de Pernambuco; Vereadora entre 1993 e 2004" Sua atuação como diretora da instituição encerrou-se em dezembro de 2015, sendo que ocupou o seu cargo o Pe. Antônio Moreno, doutor em Educação. (Cf. http://www.domboscopetrolina.g12.br/?page_id=1817. Pesquisa realizada aos 08/01/2016).
} 
humanas que, pela hipótese aqui defendida, forneceu-lhe esse olhar diferenciado como diretora de uma instituição escolar, organizando a documentação/fonte da escola para a comunidade:

É licenciada em Letras pela Faculdade de Formação de Professores de Petrolina e pela Faculdade de Filosofia, Ciências e Letras de Caruaru (PE), onde também concluiu o curso de Pedagogia (1978). Ex-professora e coordenadora da rede oficial de ensino da escola Alfa Polivalente e do Colégio Estadual de Petrolina, por seu trabalho e dedicação às grandes causas, vem assumindo a liderança em diversas instituições, imprimindo qualidade e dinamismo aos seus projetos. (Cf. http://www.domboscopetrolina.g12.br/?page_id=1817- Consulta realizada aos 08.01.2016).

Ao ser questionada sobre a relação memorial e a comunidade e de como ocorre um aproveitamento do acervo escolar, Teresinha Teixeira Coelho acrescentou:

Ele é aproveitado para as pesquisas; quase todos os trabalhos que os professores encaminham para os alunos, para... por exemplo - analise a história do fundador do colégio, Dom Malan: há registros importantes sobre a vida de Dom Malan e de outras personalidades; a história geral do Colégio D. Bosco; também de personalidades da cidade de Petrolina e da região. (COELHO,2015).

O memorial está localizado dentro do Colégio Dom Bosco, e de acordo com a monografia desenvolvida por Santos, essa Instituição educativa foi fundada aos 18 de outubro de 1926, pelo bispo D. Malan ${ }^{3}$ e inicia suas matrículas para seu funcionamento no dia 15 de março de 1927, tento como primeiro diretor o Padre Ezequiel Fraga, da congregação salesiana.

No início da sua história o Colégio Dom Bosco era uma instituição que se dedicava somente a formação de crianças e de adolescente do sexo masculino. Em 1946 era classificada pelo ministro de educação e cultura com 1.783 pontos em deferência à sua construção moderna de aspecto agradável e ao alto nível de educação no nordeste atendendo a todos os requisitos do ensino de $1^{\mathrm{a}}$ e $2^{a}$ ciclo daquela época (QUEIROZ, 1983, p. 169). De acordo com Lima (2009, p.16):

Dom Malan fez o palácio episcopal construiu casas perto da matriz, terminou a construção do hospital D. Malan, que foi iniciado por D. Cardoso, trouxe as salesianas para dirigirem o Colégio $\mathrm{N}^{\mathrm{a}} \mathrm{Sr}^{\mathrm{a}}$ Auxiliadora e criou o Colégio D. Bosco. Isso incentivou

\footnotetext{
${ }^{3}$ Dom Malan de Antonio Santana Padilha nasceu em dezembro de 1862, de origem francesa e estudou curso secundário e teologia em Paris. Entrou para a Congregação Salesiana em 1884, aos 22 anos, fazendo os votos perpétuos no ano seguinte. Veio para a América em 1889, instalando-se em Montevidéu (Uruguai), ordenando-se em 28.10.1889 (...). Em 1894, segue para Mato Grosso (...). Dedicado e empreendedor, ganhou notabilidade por sua obra apostólica nos sertões indígenas mato-grossenses. Em 1914 era sagrado em São Paulo, como Prelado de Araguaia e Bispo Auxiliar de Amisso(...)." (Cf. CARVALHO, Cid. Petrolina - Entre as cinzas do passado e os albores do porvir. Apud: SANTOS, p. 17). Dom Malan tomou posse como primeiro bispo da Diocese de Petrolina aos 15.08.1924, vindo a falecer sete anos depois. (Cf. http://www.diocesedepetrolina.org.br/ler.asp?id=12. Pesquisa realizada em 08 jan. 2016.
}

Rev. Iberoam. Patrim. Histórico-Educativo, Campinas (SP), v. 5, p. 1-11, e019011, 2019 
o progresso da cidade, muitas pessoas vieram de cidades circunvizinhas para por seus filhos para estudar e, paralelamente, a cidade começou a se desenvolver, tudo aumentou, tudo cresceu e continuará crescendo. (BRITO; LEAL, 1995, p. 272).

Com a criação dos dois colégios, o bispo sem dúvida deu uma grande contribuição para a cidade de Petrolina no que se diz respeito à educação.

Na década de 30, o Colégio Dom Bosco contava com os seguintes cursos: primário, admissão e ginasial. O seu corpo discente era formado por 65 alunos externos e 14 internos. Era assim formado o seu quadro de professores: Padre João Leal, Osmar Novais, Manoel de Paiva Neto, Sebastião Ferraz e os Drs. Epaminondas C. Albuquerque e Humberto Costa (BRITO; LEAL, 1995, p. 259).

Outro grande personagem da história do Colégio Dom Bosco, foi o Padre Manoel de Paiva Neto, que foi professor e também diretor do colégio, e durante 33 anos prestou serviços a essa instituição de ensino.

O Colégio Dom Bosco é importante para a região, pois muitos alunos foram formados por essa instituição e essa história é retratada no acervo de seu memorial.

Como preservação histórica a manutenção do arquivo é fundamental para a construção da história local. Esse trabalho retrata a relevância que essa instituição teve no processo de escolarização de meninos e de moças, em um momento que Petrolina ensaiava, ainda, os seus primeiros passos no cenário educacional e em um período marcado pela presença de uma política ainda baseada nos moldes do coronelismo. É nesta perspectiva que os arquivos escolares têm tido importantes para o campo de pesquisa em história da educação, área essa que é uma das mais crescentes dentro das pesquisas históricas. Nela estão sendo desenvolvidas várias pesquisas, inclusive, com a publicação de artigos, apresentação de trabalhos e publicações em anais de congressos nacionais e internacionais. A análise desta documentação fornece elementos significativos para a reflexão sobre o passado da instituição, das pessoas que a frequentaram, das práticas que nela circularam e, mesmo, sobre as relações que estabeleceram em seu entorno.

Esse memorial se consolida na memória escolar dos alunos que estudaram na instituição e para aqueles que ainda estudam, por terem seus registros preservados de forma adequada num espaço privilegiado da história da educação local.

O trabalho realizado no Memorial Dom Bosco, pela equipe de estudantes e de professores da Universidade de Pernambuco, constou no levantamento, na limpeza, numa nova organização e na catalogação dos documentos encontrados nesse espaço de memória. O processo de higienização 
envolveu a utilização de pincéis, do uso de máscaras e de luvas. Após esses procedimentos teve início o levantamento do material com registro dos seguintes dados: quantidade de documentos, origem, tipo, condições de uso, ano, informações básicas, informações adicionais finalizando com a digitalização e a catalogação. Foram encontrados documentações, como: correspondência de órgãos públicos, diário oficial da época, documentos de fundação da escola, boletins escolares de alunos, testamento de doação do padre Manoel de Paiva Neto (um dos diretores da escola), fotos da primeira formatura da escola em 1927, entre outros. As atividades foram desenvolvidas no período de março a outubro de 2015. Sendo que as estratégias e as formas desse procedimento serão apresentadas como modelo que poderá ser seguido por outras instituições educativas, tanto para a formação de novos pesquisadores/historiadores, quanto na valorização e no resgate da importância desses memoriais espalhados não somente pelo Brasil, mas também por várias partes do mundo.

\section{CONCLUSÕES}

Percebeu-se por meio dessa intervenção, que a partir da instituição mantenedora do Memorial D. Bosco houve uma preocupação em criar um espaço específico para preservar os documentos históricos da escola - fotografias, jornais, ofícios, troféus, móveis e etc. - chegando mesmo a pagar uma museóloga para a organização do acervo, que foi feita sem nenhum cuidado com a preservação dos documentos antigos, arquivando-os em pastas com plásticos que estavam se deteriorando devido as altas temperaturas da região.

A partir da atuação de sujeitos históricos, direção, alunos e professores realizaram uma intervenção nos documentos que foram envoltos em papel manteiga e receberam uma nova catalogação, para facilitar a sua localização e sua retirada, como também todo o acervo foi digitalizado e informatizado. Na finalização do projeto foi entregue cópias digitalizadas do acervo e apresentado à comunidade acadêmica - docentes e discentes - o novo formato de catalogação e de organização das fontes.

Esse trabalho culminará na construção de um site que constará não somente essa pesquisa como todos os outros trabalhos que serão efetuados pelo grupo de pesquisadores envolvidos nesse processo (GEPHESPE),no site estará compilado a história da educação local que será 
disponibilizado como fonte de estudo e de pesquisa para as necessidades escolares e para aqueles que se interessarem pelo tema.

O trabalho realizado no Memorial Dom Bosco remete a uma reflexão da importância da preservação de documentos escolares, dos objetos que compõem a história, pois é preciso se aproximar de uma compreensão do passado para analisar o presente. Quando se conhece a história de um determinado lugar, dos personagens que fizeram parte de sua construção e quando se pode viajar pelo tempo e reconhecer no presente vestígios do passado, é possível iniciar uma compreensão e análise do contexto no qual o sujeito histórico está inserido.

A consolidação de um centro de memória só se torna realidade, quando uma série de fatores se formam, sendo essencial a iniciativa de sujeitos que tenham consciência histórica da importância da preservação da memória escolar. Especificamente no caso do Memorial Dom Bosco, esse fator foi diagnosticado por meio do método utilizado, a história oral, que através do depoimento de uma diretora, houve o esclarecimento de sua existência e importância. Por intermédio dela, foi possível todo um trabalho de intervenção e organização para que futuros pesquisadores possam investigar o passado presente em sua documentação.

Dessa maneira, faz-se necessário persistir com iniciativas comprometidas com a preservação da memória, contribuindo no surgimento de novos centros de documentação, como também investir na formação de novos historiadores e pesquisadores preocupados com o patrimônio histórico educacional brasileiro.

\section{REFERÊNCIAS}

BRITO, Ana Clara Farias; LEAL, Ygor Barros. Jornal Pharol: Apontamentos para a Modernização em Petrolina. 1915-1920. Petrolina: Upe, 2012.

CAVALCANTE, Carlos. Dom Malan, ícone de fé e trabalho. Olinda: Livro Rápido-Elógica, 2009.

CAVAlCANTE, Carlos. Teresinha Teixeira Coelho. Uma História de Fé, Educação e Trabalho. Petrolina: Casa da Imprensa, 2010.

EDIÇÃO COMEMORATIVA. Dom Bosco Diocesano. 85 anos. Colégio Dom Bosco: Petrolina, 2011.

FURTADO, Alessandra Cristina. Os Arquivos Escolares e sua Documentação. Possibilidades $e$ Limites para a Pesquisa em História da Educação, Ribeirão Preto, v. 2, n. 2, p. 145-159, jul./dez. 2011. 
LIMA, Airon Cordeiro de. A Influência da Igreja Católica no Desenvolvimento do Município de Petrolina-PE de 1920 a 1940. Petrolina: Upe, 2009.

LUZ, Marta; RAQUEL, Déa; ARAGÃO, Euvaldo. Álbum/Roteiro: Patrimônio Histórico-Cultural edificado em Petrolina. Petrolina: Prefeitura Municipal, 1995.

LE GOFF, Jacques. História e Memória. Tradução: Bernardo Leitão et al. 2. ed. Campinas: UNICAMP, 1994.

LOZANO, Eduardo Aceves. Práticas e estilos de pesquisa na história oral contemporânea. In: AMADO, Janaína; FERREIRA, Marieta de Moraes (Coord.). Usos e abusos da história oral. Praia de Botofogo, RJ: Getúlio Vargas, 1998.

MOGARRO, Maria João. Arquivos e Educação: a Construção da Memória Educativa. Sísifo. Revista de Ciência da Educação, n. 1. set./dez. 2006.

NORA, Pierre. Entre a Memória e História: A problemática dos lugares. Revista do Programa de Estudos Pós-Graduados em História e do Departamento de História. Projeto História, São Paulo, n. 10, dezembro de 1993.

QUEIROZ, Elza. A Escola. Um Rio, Uma Cidade, Uma Escola. Recife: Norcópia, 1983.

ROCHA, Cicera M. P.; SILVA, Rosa. S. M.; ÁVILA, Virgínia P. S. Memória de professoras de escolas rurais em Juazeiro/BA e Petrolina/PE (1950-1970). Revista Cocar (online), 2018.

ROCHA, Cícera M.P. Ser professora no semiárido nordestino: a trajetória de Yolanda de Ameida (1960-1970). In: V ENCONTRO NORTE E NORDESTE DE HISTÓRIA DA EDUCAÇÃO. Anais [...]. Teresinha, 2014.

ROCHA, Honório de Queiroz. Estou presente, Petrolina! Recife: Bagaço, 2006.

SÁ Y BRITO, Maria Creusa. Petrolina. Origem, fatos, vida, uma história. Petrolina: Tribuna do Sertão, 1995.

SANTOS, José Elmo dos. Colégio Dom Bosco. 69 anos educando. Edição comemorativa dos 69 anos de fundação. [S.l], [s.d].

Recebido em: 15 de setembro de 2018 Aceito em: 30 de janeiro de 2019 